\title{
Penerapan Data Mining Untuk Memprediksi Target Produksi Berdasarkan Tingkat Penjualan Dan Banyaknya Pemesanan Produk Pada Pt. Neo National Menggunakan Metode Regresi Linier Berganda
}

\author{
Hendra Jaya, Rudi Gunawan, Rini Kustini \\ Program Studi Sistem Informasi, STMIK Triguna Dharma
}

\begin{tabular}{l}
\hline \hline Article Info \\
\hline Article history: \\
Received May $31^{\text {th }}, 2019$ \\
Revised June $12^{\text {th }}, 2019$ \\
Accepted Augs $14^{\text {th }}, 2019$
\end{tabular}

\section{Keyword:}

Data Mining,

Regresi Linier Berganda,

Prediksi Target Produksi.

\begin{abstract}
Target produksi merupakan salah satu hal penting yang harus diperhitungkan untuk memenuhi jumlah pemesanan dan penjualan suatu produk. Tentu hal ini yang mendorong PT. Neo National Medan sebagai pihak penyedia produk mencari solusi atau penyelesaian yang akan dijalankan agar permintaan dari setiap konsumen yang menjadi sasaran utama selalu terpenuhi. Dalam menentukan target produksi tersebut diperlukan perhitungan yang akurat dan pengumpulan data sample yang benar-benar akurat. Untuk itu dilakukan perhitungan mencari prediksi target produksi menggunakan data mining dengan metode regresi linier berganda, agar lebih mempermudah pihak pengguna dalam mencari jumlah target produksi yang harus dicapai.

Data mining adalah sistem pengolahan data yang dapat membantu seseorang mengambil kesimpulan dari beberapa permasalahan. Pada proses perancangan terlebih dahulu harus menentukan variabel $\mathrm{Y}, \mathrm{X} 1$ dan $\mathrm{X} 2$ berdasarkan permasalahan yang ditimbulkan lalu mengambil data akurat mengenai prediksi target produksi. Salah satu metode yang dapat digunakan adalah Regresi Linier Berganda yang dapat membantu menentukan target produksi yang akan dicapai pada bulan berikutnya. Adanya sistem ini diharapkan dapat mempermudah PT. Neo National sebagai pengguna dalam menentukan variabel yang digunakan untuk menentukan target produksi.

Hasil dari keputusan pada program ini diperoleh dari hasil variabel Y, X1 dan X2 sehingga dengan mudah dapat menentukan target produksi yang harus dicapai untuk bulan berikutnya pada PT. Neo National. Proses pengerjaannya menjadi lebih efektif dan efisien, baik dalam bidang keamanan, kecepatan dan ketepatan dalam penentuan target produksi.
\end{abstract}

Copyright (C) 2019 STMIK Triguna Dharma. All rights reserved.

\begin{tabular}{ll}
\hline First Author & \\
Nama & :Hendra Jaya \\
Kantor & :STMIK Triguna Dharma \\
Program Studi & :Sistem Informasi \\
E-Mail & :Hendrajaya@ @rigunadharma.ac.id
\end{tabular}

\section{PENDAHULUAN}

Perencanaan target produksi adalah aktivitas untuk menetapkan produk yang diproduksi, jumlah yang dibutuhkan, kapan produk tersebut harus selesai dan sumber-sumber yang dibutuhkan. Pengendalian produksi dalam sebuah perusahaan terkhusus pada perusahaan industri sangat penting ditinjau perkembangannya, dikarenakan target produksi yang dihasilkan oleh sebuah perusahaan akan berdampak pada pemesanan dan penjualan produk. Selain harus memenuhi permintaan pasar sebuah perusahaan harus memiliki stok produk digudang penyimpanan berdasarkan target yang dibutuhkan. Oleh karena itu, perusahaan harus mampu mengendalikan target produksi agar dapat meyeimbangkan antara kedua hal tersebut.

Pada dasarnya, sebuah perusahaan industri memerlukan proses yang cukup panjang untuk menghasilkan sebuah produk jadi, dari awal produksi yaitu proses bahan baku sampai menghasilkan produk 
yang siap dipasarkan. Dengan adanya proses yang berjalan secara bertahap perusahaan juga harus memenuhi permintaan pasar yang sangat pesat untuk berbagai produk yang berbeda. Dengan adanya target produksi dan persediaan produk pada gudang penyimpanan akan lebih memudahkan perusahaan untuk memenuhi semua permintaan dalam jumlah yang besar. Target produksi untuk setiap produk tentu berbeda tergantung banyaknya pemesanan dan tingginya tingkat penjualan produk tersebut, semakin tinggi tingkat penjualannya akan semakin banyak target produksinya.

Data Mining merupakan suatu cabang dari kecerdasan buatan (Artificial Intelligence). Dalam data mining terdapat beberapa jenis metode sesuai dengan pemanfaatannya diantaranya prediksi, asosiasi, klasifikasi, klastering dan estimasi. Dalam metode analisa terdapat beberapa teknik diantaranya adalah metode Regresi Linier Berganda yang merupakan hubungan secara linear antara dua atau lebih variabel independen dengan variabel dependen. Analisis ini untuk mengetahui arah hubungan antara variabel independen dengan variabel dependen apakah masing-masing variabel independen berhubungan positif atau negatif dan untuk memprediksi nilai dari variabel dependen apabila nilai variabel independen mengalami kenaikan atau penurunan.

\subsection{Rumusan Masalah}

Adapun rumusan masalah yang akan dibahas pada penelitian ini yaitu sebagai berikut :

1. Bagaimana menganalisa data produksi, pemesanan dan penjualan pada PT. Neo National Medan ?

2. Bagaimana menerapkan teknik data mining menggunakan metode Regresi Linier Berganda untuk memprediksi target produksi pada PT. Neo National Medan dengan baik dan benar?

3. Bagaimana merancang sistem yang dapat memprediksi target produksi menggunakan metode Regresi Linier Berganda?

\subsection{Batasan Masalah}

Agar penelitian yang dilakukan ini sesuai dengan permasalahan yang dibahas maka peneliti memberikan batasan masalah yaitu sebagai berikut :

1. Permasalahan yang dibahas pada penelitian ini adalah prediksi target produksi pada tahun 2018 yang diambil berdasarkan data produksi, pemesanan dan penjualan di tahun 2017.

2. Produk dan data yang dijadikan sampel adalah rill yang diproduksi oleh PT. Neo National Medan dan yang masih dipasarkan.

3. Aplikasi dirancang berbasis desktop menggunakan bahasa pemograman Visual Basic 2008.

\subsection{Tujuan Penelitian}

Adapun tujuan dari penelitian ini adalah sebagai berikut :

1. Untuk menganalisa permasalahan yang terjadi pada PT. Neo National Medan dalam memprediksi target produksi.

2. Untuk menerapkan teknik data mining menggunakan metode Regresi Linier Berganda sebagai penyelesaian masalah.

3. Untuk merancang sistem yang dapat memprediksi target produksi.

\section{METODE PENELITIAN}

\subsection{Data Mining}

Menurut Turban dkk (2006) dalam Kusrini (2009:3) Data mining adalah suatu istilah yang digunakan untuk menguraikan penemuan pengetahuan di dalam database. Data mining adalah proses yang menggunakan teknik statistik, matematika, kecerdasan buatan, dan machine learning untuk mengekstraksi dan mengidentifikasi informasi yang bermanfaat dan pengetahuan yang terakit dari berbagai database besar.

Menurut Suryadi (2010:2) Data mining adalah istilah yang memiliki beberapa padanan, seperti knowledge discovery ataupun pattern recognition. Kedua istilah tersebut sebenarnya memiliki ketepatannya masing-masing. Istilah knowledge discovery atau penemuan pengetahuan tepat digunakan karena tujuan utama data mining memang untuk mendapatkan pengetahuan yang masih tersembunyi didalam bongkahan data.

Selain istilah diatas secara umum data mining diartikan sebagai sebuah wadah yang berisi pencarian pola yang diinginkan dalam database yang besar untuk membantu pengambilan keputusan di waktu yang akan datang. Data mining berhubungan dengan sub-area statistik yang disebut exploratory data analysis, yang mempunyai tujuan sama dan bersandar pada ukuran-ukuran statistik. Data mining juga berhubungan erat dengan sub-area artificial intelligent yang disebut juga knowledge discovery dan machine learning. 
Menurut Pramudiono dalam Kusrini (2009:4) Data mining adalah analisis otomatis dari data yang berjumlah besar atau kompleks dengan tujuan untuk menemukan pola atau kecenderungan yang penting yang biasanya tidak disadari keberadaannya.

Banyak definisi bagi istilah ini dan belum ada yang membakukan atau disepakati semu pihak namun demikian, istilah ini memilki hakikat (notion) sebagai disiplin ilmu yang tujuan utamanya adalah untuk menemukan, menggali atau menambang pengetahuan dari data atau informasi yang kita miliki. Kegiatan inilah yang menjadi garapan atau perhatian utama dari disiplin ilmu data mining.

\subsubsection{Pengelompokan Data mining}

Menurut Larose (2005) dalam Kusrini (2009:10) Teknik data mining dibagi beberapa bagian berdasarkan tugas yang dapat dilakukan, yaitu :

1. Deskripsi

Terkadang peneliti dan analisi secara sederhana ingin mencoba mencari cara menggambarkan pola dan kecenderungan yang terdapat dalam data.

2. Estimasi

Estimasi hampir sama dengan klasifikasi, kecuali variabel target estimasi lebih ke arah numerik dari pada ke arah kategori. Model dibangun menggunakan record lengkap yang meyediakan nilai dari variabel target sebagai nilai prediksi.

3. Prediksi

Prediksi hampir sama dengan klasifikasi dan estimasi, kecuali bahwa dalam prediksi nilai dari hasil akan ada dimasa mendatang. Beberapa metode dan teknik yang digunakan dalam klasifikasi dan estimasi dapat pula digunakan (untuk keadaan yang tepat) untuk prediksi.

4. Klasifikasi

Dalam klasifikasi, terdapat target variabel kategori. Sebagai contoh, penggolongan pendapatan dapat dipisahkan dalam tiga kategori, yaitu pendapatan tinggi, pendapatan sedang dan pendapatan sedang.

5. Pengklusteran

Pengklusteran merupakan pengelompokan record, pengamatan, atau memperhatikan dan membentuk kelas objek-objek yang memiliki kemiripan. Kluster adalah kumpulan record yang memilki kemiripan satu dengan yang lainnya dan memilki ketidak miripan dengan record-record dalam kluster lain.

6. Asosiasi

Tugas asosiasi dalam data mining adalah menemukan atribut yang muncul dalam satu waktu. Dalam dunia bisnis lebih umum disebut analisis keranjang belanja.

\subsubsection{Metode Regresi Linier Berganda}

Analisis yang memiliki variabel bebas lebih dari satu disebut analisis regresi linier berganda. Teknik regresi linier berganda digunakan untuk mengetahui ada tidaknya pengaruh signifikan dua atau lebih variabel bebas $(\mathrm{X} 1, \mathrm{X} 2, \mathrm{X} 3, \ldots, \mathrm{Xk})$ terhadap variabel terikat $(\mathrm{Y})$. Model regresi linier berganda untuk populasi dapat ditunjukkan sebagai berikut :

(Amrin, 2016:75)

$$
\mathrm{Y}=\beta 0+\beta 1 \mathrm{X} 1+\beta 2 \mathrm{X} 2+\ldots+\beta \mathrm{nXn}+\mathrm{e}
$$

Model regresi linier berganda untuk populasi diatas dapat ditaksir dengan model regresi linier berganda untuk sampel, yaitu :

Keterangan :

$$
\hat{\mathrm{Y}}=\mathrm{b} 0+\mathrm{b} 1 \mathrm{X} 1+\mathrm{b} 2 \mathrm{X} 2+\ldots+\mathrm{bnXn}
$$

$$
\begin{array}{ll}
\hat{\mathrm{Y}} & =\text { nilai penduga bagi variabel } \mathrm{Y} \\
\mathrm{a} & =\text { dugaan bagi parameter konstanta } \\
\mathrm{b} 1, \mathrm{~b} 2, \ldots \mathrm{bk} & =\text { dugaan bagi parameter konstanta } \\
\mathrm{X} 1, \mathrm{X} 2, \ldots . \mathrm{Xn}= & \text { variabel bebas }
\end{array}
$$

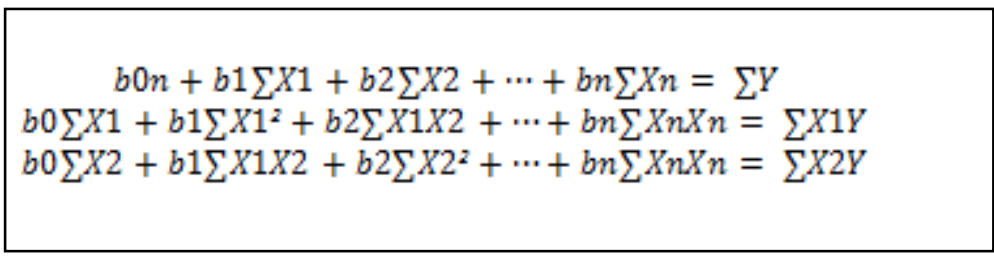


Nilai koefisien regresi b1 dan b2 jika :

1. bernilai 0 , maka tidak ada pengaruh variabel bebas $\mathrm{X} 1$ dan $\mathrm{X} 2$ terhadap variabel tak bebas $\mathrm{Y}$.

2. bernilai negatif maka terjadi hubungan yang berbalik arah antara variabel bebas X1 dan X2 dengan variabel tak bebas Y.

3. bernilai positif maka terjadi hubungan yang searah antara variabel bebas X1 dan X2 dengan variabel tak bebas Y.

\section{ANALISIS DAN HASIL}

Kebijakan atau keputusan selama ini yang dilakukan oleh manager untuk menentukan pengaruh pencapaian target produksi dengan cara mengumpulkan hasil-hasil nilai produksi dan beberapa data-data yang menunjang kriteria-kriteria yang telah ditetapkan. Pengaruh total pemesanan produk dan total penjualan untuk menentukan target produksi yang dilakukan secara manual sangatlah membutuhkan waktu yang sangat lama. Untuk mengatasi permasalahan dalam menentukan pengaruh target produksi yang ada pada PT. Neo National Medan, maka diperlukan suatu alat analisis bagi manager, supervisor dan manager produksi untuk memperkirakan target tersebut.

Alat analisis tersebut berupa aplikasi penunjang keputusan berbasis komputer yang mengimplementasikan data mining menggunakan prediksi yang didalamnya sudah dilengkapi metode Regresi Linear Berganda. Dengan ketersediaan data produksi yang lengkap, maka data mining dapat menggali informasi yang tersirat dari kumpulan data produksi yang diperoleh dari perusahaan tersebut.

\subsection{Menentukan Variabel dan Koofisien Regresi}

Data akan diolah dengan menerapkan data mining dengan penggunaan metode regresi linear berganda dalam proses untuk prediksi target produksi. Beberapa atribut atau komponen variabel yang digunakan yaitu terlihat pada Tabel 3.1 sebagai berikut.

Tabel 3.1 Data Produksi Tahun 2017

\begin{tabular}{|c|c|c|c|}
\hline \multirow{2}{*}{ Bulan } & \multicolumn{3}{|c|}{$\mathbf{2 0 1 7}$} \\
\cline { 2 - 4 } & Penjualan $\left(\mathbf{X}_{\mathbf{1}}\right)$ & Pemesanan $\left(\mathbf{X}_{\mathbf{2}}\right)$ & Target Produksi (Y) \\
\hline Januari & 8000 & 8000 & 9000 \\
\hline Februari & 9000 & 9000 & 9000 \\
\hline Maret & 9500 & 9500 & 9500 \\
\hline April & 9000 & 9000 & 9000 \\
\hline Mei & 9500 & 9000 & 9500 \\
\hline Juni & 9000 & 9000 & 9500 \\
\hline Juli & 8500 & 8500 & 9500 \\
\hline Agustus & 8000 & 8000 & 9000 \\
\hline September & 8000 & 8000 & 8000 \\
\hline Oktober & 7500 & 7000 & 8000 \\
\hline Nopember & 9000 & 9000 & 8500 \\
\hline Desember & 9000 & 9000 & 9500 \\
\hline
\end{tabular}

Kemudian data tersebut akan dibulatkan seperti Tabel 3.2 sebagai berikut :

Tabel 3.2 Data Produksi Tahun 2017 yang dibulatkan

\begin{tabular}{|c|c|c|c|}
\hline \multirow{2}{*}{ Bulan } & \multicolumn{3}{|c|}{2017} \\
\cline { 2 - 4 } & Penjualan $\left(\mathrm{X}_{1}\right)$ & Pemesanan $\left(\mathrm{X}_{2}\right)$ & Target Produksi (Y) \\
\hline Januari & 8 & 8 & 9 \\
\hline Februari & 9 & 9 & 9 \\
\hline Maret & 9.5 & 9.5 & 9.5 \\
\hline April & 9 & 9 & 9.5 \\
\hline Mei & 9.5 & 9 & 9.5 \\
\hline Juni & 9 & 9 & 9.5 \\
\hline Juli & 8.5 & 8.5 & \\
\hline
\end{tabular}




\begin{tabular}{|c|c|c|c|}
\hline Agustus & 8 & 8 & 9 \\
\hline September & 8 & 8 & 8 \\
\hline Oktober & 7.5 & 7 & 8 \\
\hline Nopember & 9 & 9 & 8.5 \\
\hline Desember & 9 & 9 & 9.5 \\
\hline
\end{tabular}

Dari tabel yang ada di atas, maka diperoleh perhitungan sebagai berikut :

1. Pada bulan Januari

Total penjualan $\left(\mathrm{X}_{1}\right)$ yang ada yaitu : 8 , total pemesanan $\left(\mathrm{X}_{2}\right)$ sebanyak 8 dan total produksi $(\mathrm{Y})$ sebanyak

9. Maka $: X 1^{2}=64, X 2^{2}=64, Y^{2}=81, Y^{* X} 1=72, Y * X 2=72, X 1 * X 2=64$

2. Pada bulan Februari

Total penjualan $\left(\mathrm{X}_{1}\right)$ yang ada yaitu : 9 , total pemesanan $\left(\mathrm{X}_{2}\right)$ sebanyak 9 dan total produksi $(\mathrm{Y})$ sebanyak 9. Maka $\mathrm{X} 1^{2}=81, \mathrm{X} 2^{2}=81, \mathrm{Y}^{2}=81, \mathrm{Y}^{*} \mathrm{X} 1=81, \mathrm{Y}^{*} \mathrm{X} 2=81, \mathrm{X} 1 * \mathrm{X} 2=81$.

3. Pada bulan Maret

Total penjualan $\left(\mathrm{X}_{1}\right)$ yang ada yaitu : 9,5, total pemesanan $\left(\mathrm{X}_{2}\right)$ sebanyak 9,5 dan total produksi (Y) sebanyak 9,5. Maka X12 $1^{2} 90,25, \mathrm{X} 2^{2}=90,25, \mathrm{Y}^{2}=90,25, \mathrm{Y}^{*} \mathrm{X} 1=90,25, \mathrm{Y}^{*} \mathrm{X} 2=90,25, \mathrm{X} 1 * \mathrm{X} 2=$ 90,25 .

4. Pada bulan April

Total penjualan $\left(\mathrm{X}_{1}\right)$ yang ada yaitu : 9 , total pemesanan $\left(\mathrm{X}_{2}\right)$ sebanyak 9 dan total produksi $(\mathrm{Y})$ sebanyak 9. Maka $\mathrm{X} 1^{2}=81, \mathrm{X} 2^{2}=81, \mathrm{Y}^{2}=81, \mathrm{Y}^{*} \mathrm{X} 1=81, \mathrm{Y}^{*} \mathrm{X} 2=81, \mathrm{X} 1 * \mathrm{X} 2=81$.

5. Pada bulan Mei

Total penjualan $\left(\mathrm{X}_{1}\right)$ yang ada yaitu : 9,5 , total pemesanan $\left(\mathrm{X}_{2}\right)$ sebanyak 9 dan total produksi $(\mathrm{Y})$ sebanyak 9,5. Maka X12 $1^{2}=90,25, \mathrm{X}^{2}=81, \mathrm{Y}^{2}=90,25, \mathrm{Y} * \mathrm{X} 1=90,25, \mathrm{Y} * \mathrm{X} 2=85,5, \mathrm{X} 1 * \mathrm{X} 2=85,5$.

6. Pada bulan Juni

Total penjualan $\left(\mathrm{X}_{1}\right)$ yang ada yaitu : 9 , total pemesanan $\left(\mathrm{X}_{2}\right)$ sebanyak 9 dan total produksi $(\mathrm{Y})$ sebanyak 9,5. Maka X $1^{2}=81, \mathrm{X} 2^{2}=81, \mathrm{Y}^{2}=90,25, \mathrm{Y}^{*} \mathrm{X} 1=85,5, \mathrm{Y} * \mathrm{X} 2=85,5, \mathrm{X} 1 * \mathrm{X} 2=81$

7. Pada bulan Juli

Total penjualan $\left(\mathrm{X}_{1}\right)$ yang ada yaitu : 8,5, total pemesanan $\left(\mathrm{X}_{2}\right)$ sebanyak 8,5 dan total produksi $(\mathrm{Y})$ sebanyak 9,5. Maka X12 $1^{2} 72,25, \mathrm{X} 2^{2}=72,25, \mathrm{Y}^{2}=90,25, \mathrm{Y}^{* \mathrm{X}} 1=80,75, \mathrm{Y}^{*} \mathrm{X} 2=80,75, \mathrm{X} 1 * \mathrm{X} 2=$ 72,25 .

8. Pada bulan Agustus

Total penjualan $\left(\mathrm{X}_{1}\right)$ yang ada yaitu : 8 , total pemesanan $\left(\mathrm{X}_{2}\right)$ sebanyak 8 dan total produksi (Y) sebanyak 9. Maka $\mathrm{X} 1^{2}=64, \mathrm{X} 2^{2}=64, \mathrm{Y}^{2}=81, \mathrm{Y}^{*} \mathrm{X} 1=72, \mathrm{Y} * \mathrm{X} 2=72, \mathrm{X} 1 * \mathrm{X} 2=64$.

9. Pada bulan September

Total penjualan $\left(\mathrm{X}_{1}\right)$ yang ada yaitu : 8 , total pemesanan $\left(\mathrm{X}_{2}\right)$ sebanyak 8 dan total produksi $(\mathrm{Y})$ sebanyak 8. Maka X12 $=64, \mathrm{X} 2^{2}=64, \mathrm{Y}^{2}=64, \mathrm{Y}^{*} \mathrm{X} 1=64, \mathrm{Y}^{*} \mathrm{X} 2=64, \mathrm{X} 1 * \mathrm{X} 2=64$.

10. Pada bulan Oktober

Total penjualan $\left(\mathrm{X}_{1}\right)$ yang ada yaitu : 7,5, total pemesanan $\left(\mathrm{X}_{2}\right)$ sebanyak 7 dan total produksi $(\mathrm{Y})$ sebanyak 8. Maka X12 $1^{2}=56,25, \mathrm{X}^{2}=49, \mathrm{Y}^{2}=64, \mathrm{Y} * \mathrm{X} 1=60, \mathrm{Y} * \mathrm{X} 2=56, \mathrm{X} 1 * \mathrm{X} 2=53,5$.

11. Pada bulan Nopember

Total penjualan $\left(\mathrm{X}_{1}\right)$ yang ada yaitu : 9 , total pemesanan $\left(\mathrm{X}_{2}\right)$ sebanyak 9 dan total produksi $(\mathrm{Y})$ sebanyak 8,5. Maka $\mathrm{X} 1^{2}=81, \mathrm{X} 2^{2}=81, \mathrm{Y}^{2}=72,25, \mathrm{Y}^{*} \mathrm{X} 1=76,5, \mathrm{Y}^{*} \mathrm{X} 2=76,5, \mathrm{X} 1 * \mathrm{X} 2=81$.

12. Pada bulan Desember

Total penjualan $\left(\mathrm{X}_{1}\right)$ yang ada yaitu : 9 , total pemesanan $\left(\mathrm{X}_{2}\right)$ sebanyak 9 dan total produksi $(\mathrm{Y})$ sebanyak 9,5. Maka X $1^{2}=81, \mathrm{X} 2^{2}=81, \mathrm{Y}^{2}=90,25, \mathrm{Y} * \mathrm{X} 1=85,5, \mathrm{Y} * \mathrm{X} 2=85,5, \mathrm{X} 1 * \mathrm{X} 2=81$.

a. Kemudian masukkan angka yang telah didapat pada rumus persamaan, sehingga diperoleh hasilnya sebagai berikut :

$$
\begin{aligned}
& b 0 n+b 1 \sum X 1+b 2 \sum X 2+\cdots+b n \sum X n=\sum Y \\
& b 0 \sum X 1+b 1 \sum X 1^{2}+b 2 \sum X 1 X 2+\cdots+b n \sum X n X n=\sum X 1 Y \\
& b 0 \sum X 2+b 1 \sum X 1 X 2+b 2 \sum X 2^{2}+\cdots+b n \sum X n X n=\sum X 2 Y
\end{aligned}
$$

b0 $(12)+b 1(104)+b 2(103)=108$

b0 $(104)+b 1(906)+b 2(897,5)=938,75$

b0 $(103)+b 1(897,5)+b 2(889,5)=930$
(Persamaan 1)

(Persamaan 2)

(Persamaan 3) 
b. Kemudian ketiga persamaan d atas diselesaikan hingga memperoleh nilai pada b0, b1, b2. Langkah-langkah penyelesaiannya adalah sebagai berikut :

Pertama, persamaan 1 dan 2 dieliminasi

(12) b0 + (104) b1 + (103) b2 = 108

$(104) b 0+(906) b 1+(897,5) b 2=938,75$

\begin{tabular}{l|l} 
& x 36
\end{tabular}

$312 b 0+2704 b 1+2678 b 2=2808$

$312 b 0+2718 b 1+2692,5 b 2=2816,25$

$0+(-14) b 1+(-14,5) b 2=-8,25$

(Persamaan 4)

Kedua, persamaan 1 dan 3 dieliminasi

(12) b0 + (104) b1 + (103) b2 = 108

$(103) b 0+(897,5) b 1+(889,5) b 2=930$

\begin{tabular}{l|l}
$\mathrm{x} 12$ & $\mathrm{x} 103$
\end{tabular}

$1236 \mathrm{~b} 0+10712 \mathrm{~b} 1+10609 \mathrm{~b} 2=11124$

$1236 b 0+10770 b 1+10674 b 2=11160$

$0+(-58) b 1+(-65) b 2=-36$

(Persamaan 5)

Ketiga, persamaan $\mathbf{4}$ dan 5 dieliminasi

$0+(-14) b 1+(-14,5) b 2=-8,25$

$0+(-58) b 1+(-65) b 2=-36$

x 29 x 7

\begin{tabular}{ccc}
\hline $\begin{array}{c}(-406) b 1+(-420,5) b 2 \\
(-406) b 1+(-455) b 2=-252\end{array}$ & \\
\hline $0 \quad+\quad 34,5$ b2 & $=12,75$ \\
b2 & $=12,75 / 34,5$ \\
b2 & $=\mathbf{0 , 3 6 9 5 6 5}$
\end{tabular}

Keempat, masukkan nilai b2 kepersamaan 4 dengan mensubsitusikan

$0+(-14) b 1+(-14,5) b 2=-8,25$

$(-14) \mathrm{b} 1+(-18)(0,369565)=-8,25$

$(-14) \mathrm{b} 1+(-5,358692)=-8,25$

$(-14) \mathrm{b} 1=-5,358692+(-8,25)$

$(-14) b 1=-13,608692$

b1 $=(-13,608692) /(-14)$

b1 $=0,972049$

Kelima, masukkan nilai b1 dan b2 ke persamaan 1 dengan mensubsitusikan

b0 $(12)+$ b1 (104) + b2 (103) $=108$

b0 $(12)+(0,972049)(104) b 1+(0,369565)(103) b 2=108$

b0 $(12)+101,0931677 \mathrm{~b} 1+38,0652174 \mathrm{~b} 2=108$

b0 $(12)+139,158385=401$

b0 $(12)=108-139,158385$

b0 $(12)=-31,15839$

b0 $=-31,15839 / 12 \quad$ b0 $=\mathbf{- 2 , 5 9 6 5 3 2}$

Jadi sekarang telah diketahui nilai b0, b1, b2 dimana nilai-nilainya adalah sebagai berikut :

b0 = $=-2,596532$

$\mathrm{b} 1 \quad=0,972049$

b2 $=0,369565$

sehingga persamaan regresinya menjadi :

$$
Y=-2,596532+0,972049(X 1)+0,369565(X 2)
$$


Setelah mendapatkan persamaan regresi linear bergandanya maka dapat ditentukan prediksi target produksi pada PT. Neo National Medan, berikut ini akan disubtitusikan nilai sample di bulan Januari kedalam persamaan regresi yang sudah didapat :

$\mathrm{Y}=-2,596532+0,972049(\mathrm{X} 1)+0,369565(\mathrm{X} 2)$

$\mathrm{Y}=-2,596532+0,972049(9)+0,369565(9)$

$\mathrm{Y}=-2,596532+8,7484+3,3260$

$\mathrm{Y}=-2,596532+12,0742$

$\mathrm{Y}=9,478002=9500$ (pembulatan)

Sehingga, target produksi pada bulan januari adalah 9.500 pcs

\subsection{Tampilan Menu Utama}

Setelah proses login berhasil, admin akan diarahkan ke menu utama dimana pada menu utama terdapat empat sub menu pengolahan data yang dapat diakses, yaitu menu data, menu proses, menu hasil dan menu laporan. Namun, apabila proses login tidak berhasil maka sistem akan kembali ke halaman login, dan sistem akan meminta untuk memasukkan kembali username dan password yang benar. Halaman menu utama dapat dilihat pada gambar 4.2 berikut ini :

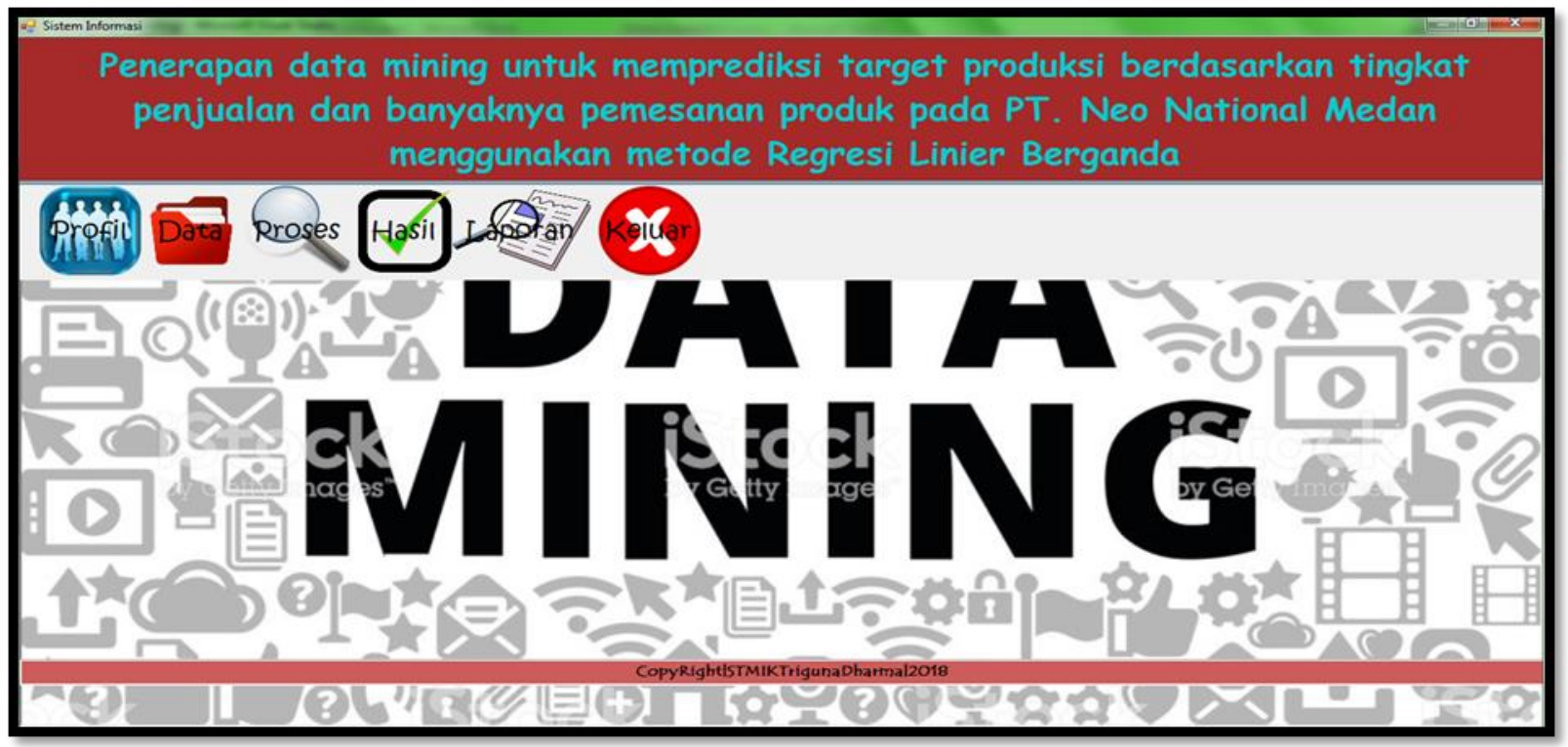

\subsection{Tampilan Sub Menu Data}

Pada sub menu data terdapat proses input data produksi di tahun 2017 yang mencangkup data penjualan, data pemesanan dan target produksi. Input data produksi yang dimaksud adalah proses menambah, mengubah, menyimpan dan menghapus data produksi yang terdapat pada database.

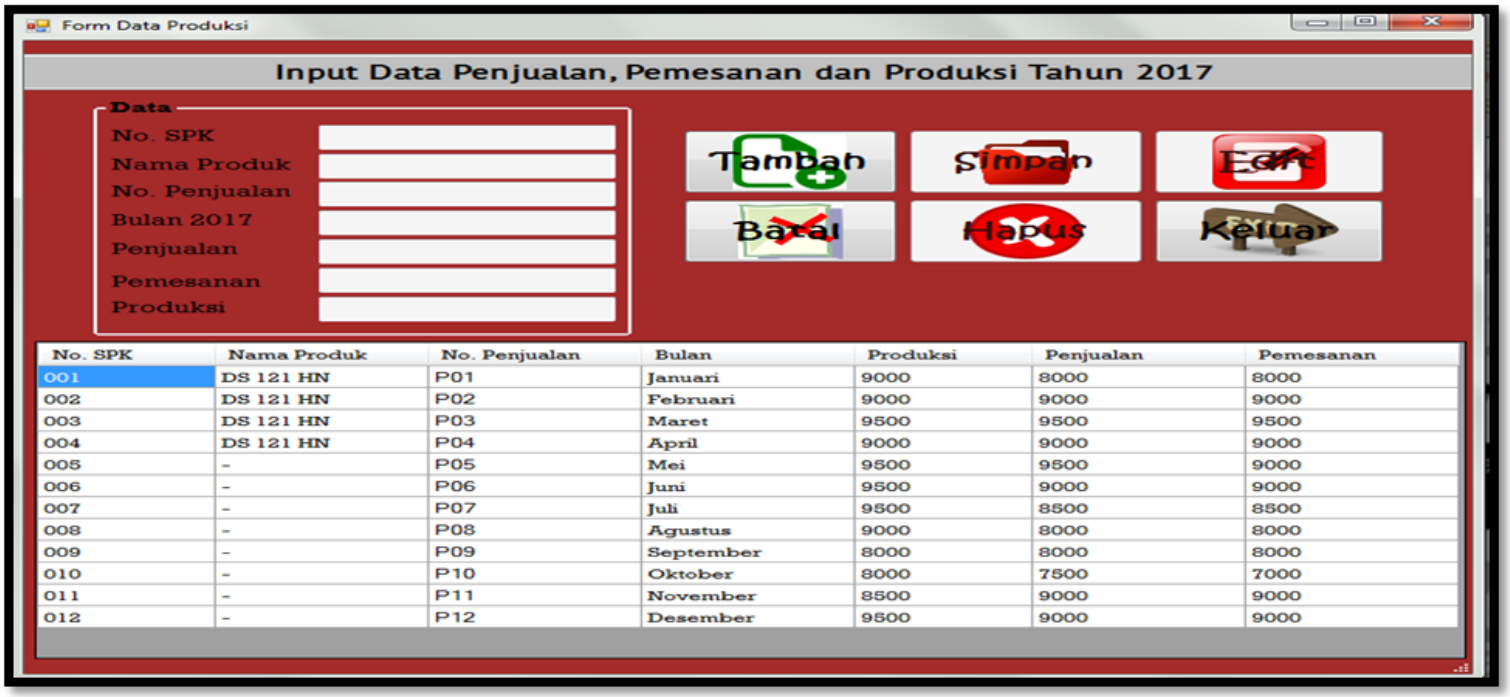




\subsection{Tampilan Sub Menu Proses Persamaan Regresi}

Pada form proses merupakan tampilan antarmuka untuk melakukan proses regresi linier berganda untuk memprediksi target produksi. Berikut adalah gambar hasil hasil implementasi dari rancangan antarmuka form proses regresi.

Adapun fungsi-fungsi dari tombol yang terdapat dalam form proses persamaan regresi yaitu simpan berfungsi untuk mengolah data serta menyimpan proses persamaan. Kemudian, setelah seluruh proses regresi selesai klik tombol simpan maka akan tampil kotak dialog persamaan berhasil disimpan seperti gambar di bawah ini :

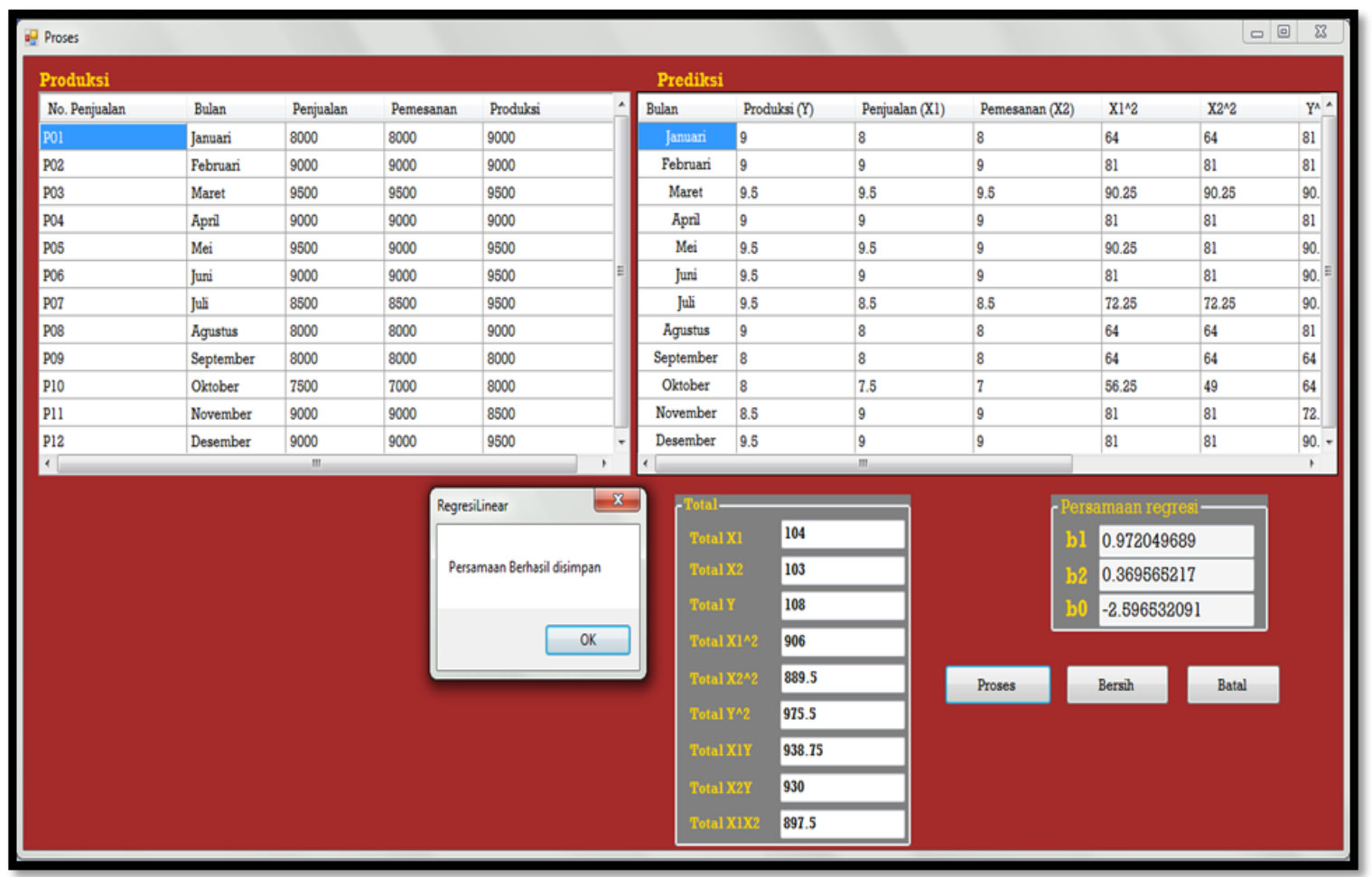

Setelah proses penginputan data dan proses persamaan regresi berhasil dilakukan, maka sistem akan memproses hasil dari pencarian target produksi untuk tahun 2018 sesuai dengan rumusan masalah yang telah ditentukan pada bab sebelumnya, yang dimana sistem ini dibuat untuk menentukan target produksi tahun 2018. Adapun halaman form hasil target produksi pada tahun 2018 dapat dilihat pada gambar 4.6 berikut ini :

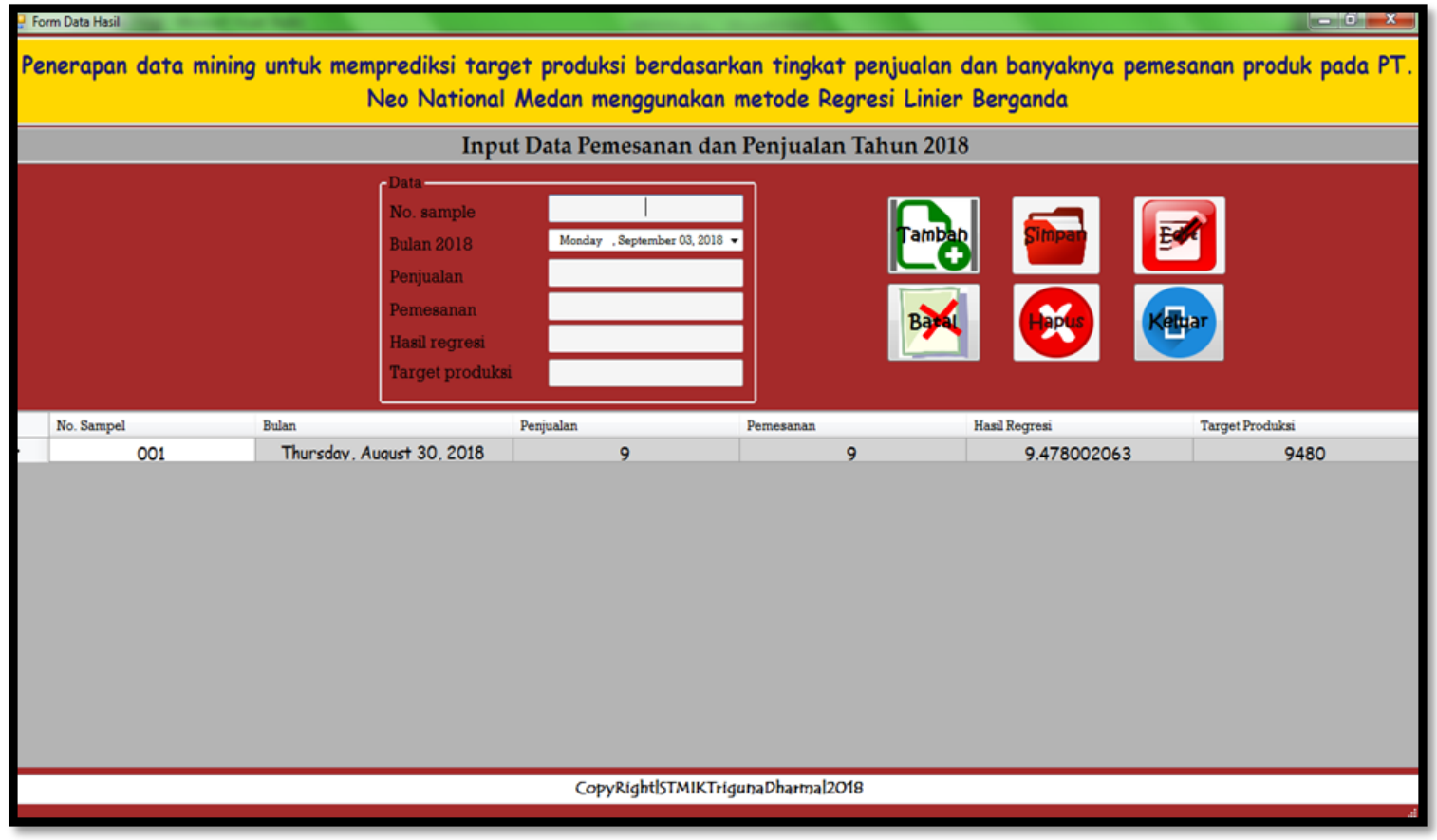


Adapun fungsi-fungsi tombol pada form hasil target produksi tahun 2018 adalah sebagai berikut :

Setelah dilakukan pengujian maka menghasilkan sebuah laporan yaitu laporan target produksi tahun 2018 yang harus dicapai seperti yang terlihat pada gambar di bawah ini :

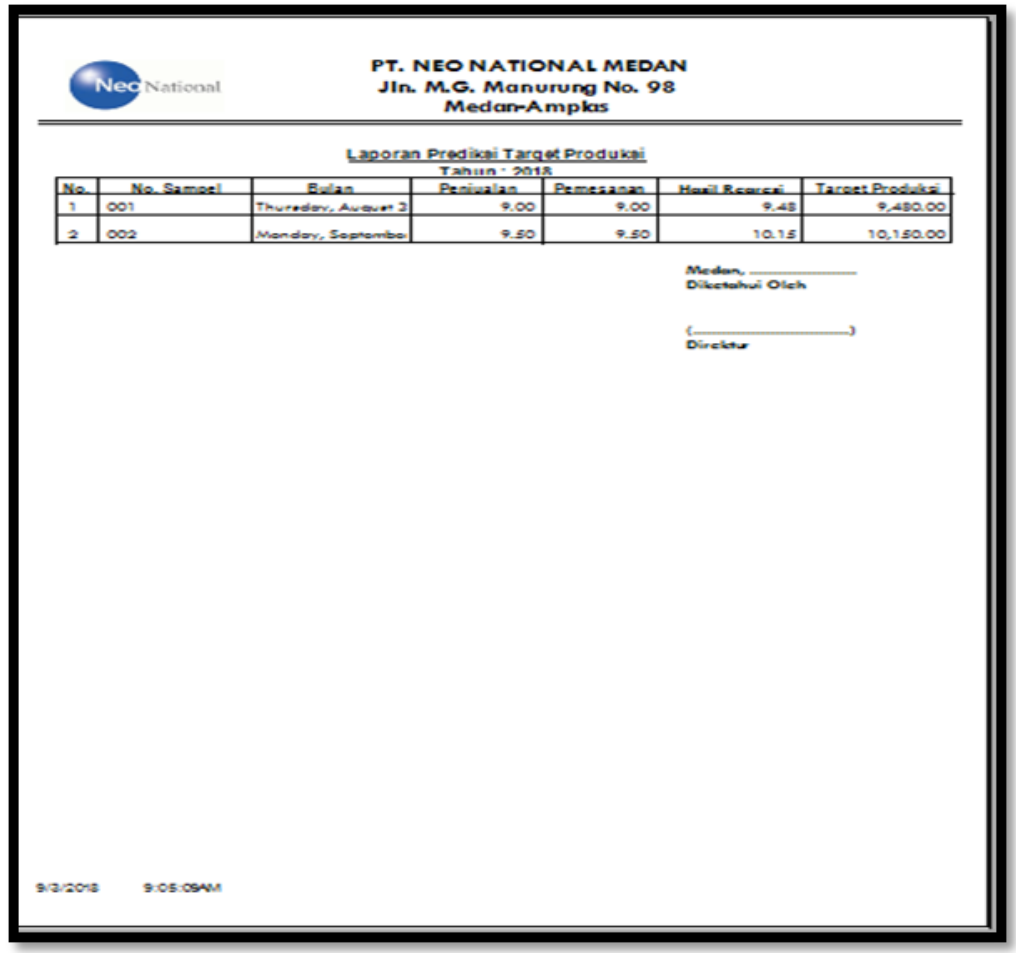

\section{KESIMPULAN}

1. Adapun cara menganalisa data produksi, penjualan dan pemesanan pada tahun 2017 adalah dengan cara terlebih dahulu mengumpulkan setiap data akurat yang terjadi setiap bulannya, kemudian data tersebut dikelompokkan dan selanjutnya dilakukan pembulatan agar data yang akan dihitung tidak terlalu besar nominalnya.

2. Untuk mengimplementasikan teknik data mining menggunakan metode Regresi Linier Berganda dalam pemecahan masalah menentukan target produksi adalah dengan cara, terlebih dahulu tentukan variabel $\mathrm{Y}$, $\mathrm{X} 1$ dan $\mathrm{X} 2$, selanjutnya hitung nilai dari setiap perpangkatan, lalu hitung menggunakan rumus untuk mencari nilai a, b1 dan b2, setelah nilai a, b1 dan b2 ditentukan saatnya pengujian sample untuk menentukan prediksi target produksi yang akan dicapai.

3. Untuk merancang sebuah sistem prediksi menggunakan teknik data mining menggunakan metode Regresi Linier Berganda dapat digunakan bahasa pemrograman berbasis desktop sehingga menjadi sebuah aplikasi prediksi yang dapat digunakan secara cepat dan jauh lebih akurat.

\section{REFERENSI}

[1] Hermawati Astuti Fajar. 2013. Data Mining. Yogyakarta : Andi

[2] Kusrini \& Emha Taufiq Luthfi. 2009. Algoritma Data Mining. Yogyakarta : Andi.

[3] Madcoms. 2011. Membangun Aplikasi Pembelian - Penjualan dan Inventori dengan MS. Access. Yogyakarta : Andi.

[4] Tata Sutabri. 2012. Analisis Sistem informasi. Yogyakarta : Andi.

[5] Rahmat Priyanto. 2008. Langsung Bisa Visual Basic.Net 2008. Bandung : Andi.

[6] Rosa, A.S., \& Shalahuddin, M. 2014. Rekayasa Perangkat Lunak Terstruktur dan

Berorientasi Objek. Bandung : Informatika 